
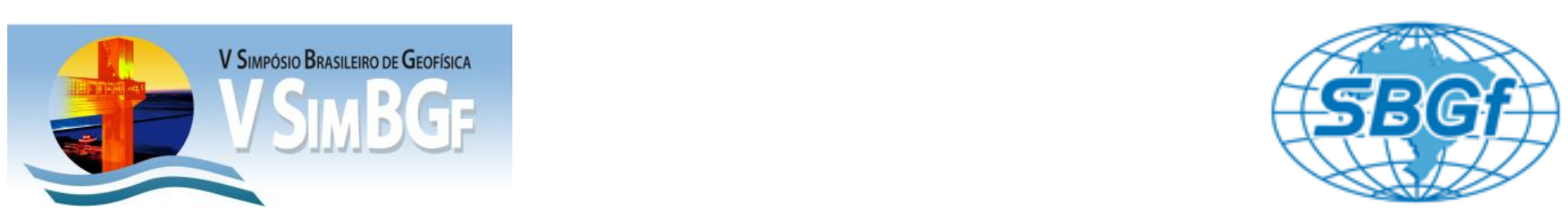

\title{
Utilização de sismos regionais para a determinação de um modelo de velocidades para a Província Borborema - NE do Brasil
}

Hasan Shihadeh, Aderson do Nascimento, Joaquim Ferreira (Universidade Federal do Rio Grande do Norte - UFRN, Natal)

Copyright 2012, SBGf - Sociedade Brasileira de Geofísica

Este texto foi preparado para a apresentação no V Simpósio Brasileiro de Geofísica, Salvador, 27 a 29 de novembro de 2012. Seu conteúdo foi revisado pelo Comitê Técnico do V SimBGf, mas não necessariamente representa a opinião da SBGf ou de Técnico do V SimBGf, mas não necessariamente representa a opinião da SBGf ou de propósitos comerciais sem prévia autorização da SBGf.

\section{Resumo}

The main objective of this work is to develop a more appropriate model 1D lithosphere of the Borborema province and determine the parameters of this model $(P$ wave velocity and thickness) for use in the epicentral location of installed networks in this region. Thus we selected 12 events with a maximum horizontal uncertainties $5 \mathrm{~km}$. The selection of earthquakes with magnitude greater than 3.0 enables the event is also recorded in several stations so that increase the reliability of the model.

\section{Introdução}

Um dos procedimentos fundamentais da sismologia é a localização de epicentros. Para que isso aconteça é necessário saber a variação da velocidade da onda $P$ de acordo com a profundidade (modelo de velocidades) e consequentemente os tempos de percurso da onda $\mathrm{P}$. O método mais utilizado na determinação epicentral é o método de mínimos quadrados de Geiger (1910), onde usa-se um epicentro inicial e um processo iterativo de aproximação até obter uma localização precisa do epicentro.

O primeiro modelo global desenvolvido foi o de Jeffreys \& Bullen (1940), sendo mais representativo das velocidades do manto superior em regiões de borda de placa, devido à influência dos terremotos em zonas ativas. Outro modelo conhecido é o de Herrin (1968), no qual possui uma distribuição de estações e epicentros mais uniforme, incluindo explosões nucleares. Assim, seu modelo é mais representativo da estrutura abaixo dos continentes e é bastante utilizado em softwares de determinação epicentral. O modelo médio global mais aceito na atualidade é o IASP91 (Kennet \& Engdahl, 1991) e as diferenças mais significativas entre este modelo e o de Jeffreys \& Bullen (1940) estão no manto superior e no núcleo. Posteriormente, Kennett et al. (1995) começou com as melhores características do IASP91 (Kennet \& Engdahl, 1991) e aperfeiçoou o modelo de referência global para AK 135 (Kennett et al., 1995), tendo como diferença o gradiente de velocidade para a camada D" e a linha base para tempos de percurso da onda S.

Em 1990, foi desenvolvido por Kwitko \& Assumpção (1990), um modelo de velocidades para o Brasil denominado modelo BR. Esse modelo adaptado para o Brasil tinha o objetivo de minimizar os resíduos, aumentando assim a precisão na determinação de epicentros de sismos no Brasil. Em seguida, outro modelo adequado a estrutura litosférica do Brasil foi desenvolvido por Ardito (2009), chamado de New BR. O Laboratório Sismológico da UFRN desenvolve há quase vinte anos, estudos de sismicidade no nordeste brasileiro, região onde se encontra uma das maiores atividades sísmicas intraplaca do país (Figura 1). Por isso, o conhecimento da espessura crustal é muito importante para se vincular modelos geotectônicos e gravimétricos, além de proporcionar subsídios para se estabelecer um modelo de velocidades de propagação de ondas sísmicas regionalmente. Desta forma, o presente trabalho tem como objetivo a determinação de um modelo de velocidades válido para a Província Borborema, no nordeste do Brasil.

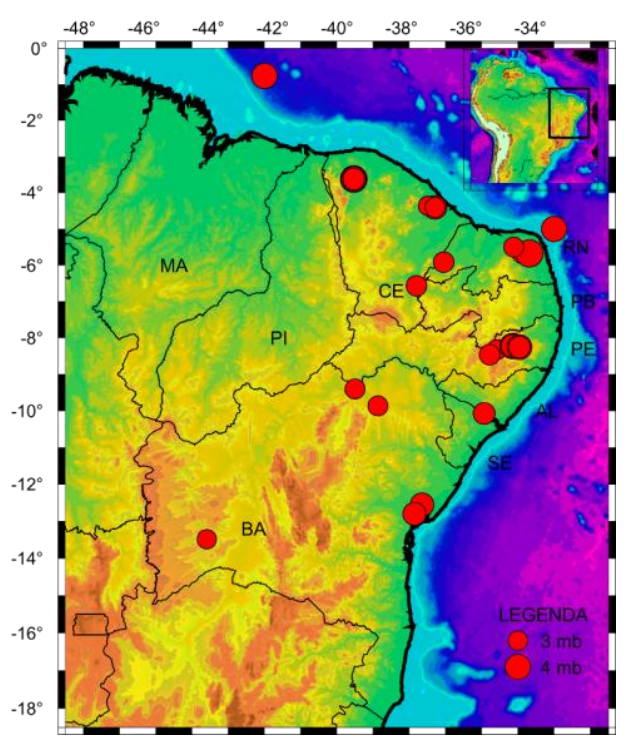

Figura 1 - Epicentros (círculos vermelhos) de eventos com magnitude igual ou superior a 3.0, de 2001 a 2011, no nordeste do Brasil.

\section{Área de estudo}

A Província Borborema possui uma área de aproximadamente $450.000 \mathrm{~km}^{2}$ sendo 0 seu limite ocidental a Bacia do Parnaíba. A sul, o limite é definido pelo Cráton São Francisco. Os limites norte e leste constituem-se por bacias costeiras da margem continental (Jardim de Sá, 1994). 


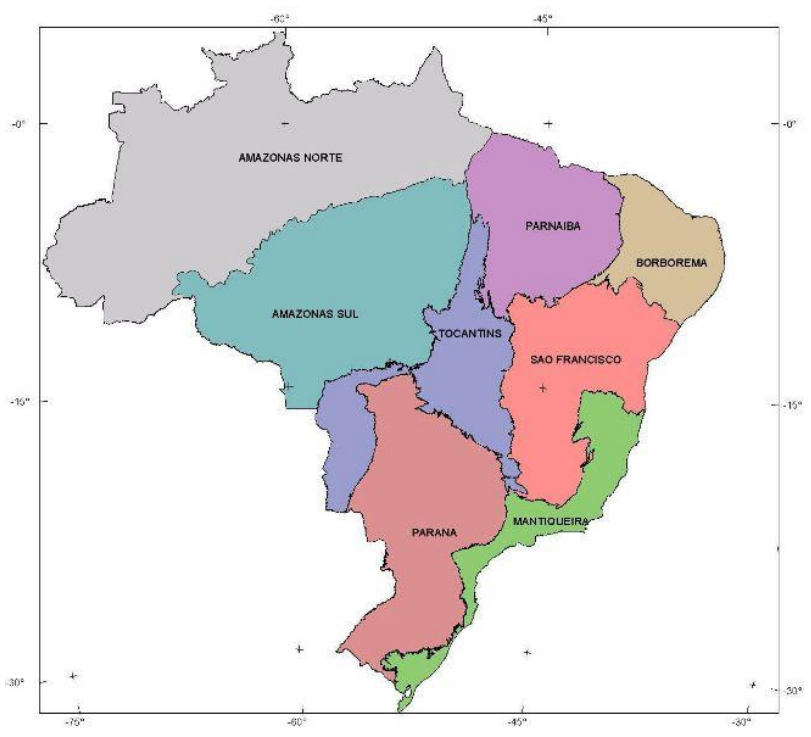

Figura 2 - Mapa de localização das províncias tectônicas (CPRM, 2001).

A Província Borborema tem como característica básica a atuação do ciclo orogênico Brasiliano $(600 \pm 100 \mathrm{Ma})$, importante evento tectônico de formação de rochas e estruturas dúcteis (Jardim de Sá, 1994). Deste modo, para o entendimento da evolução geotectônica da Província Borborema deve-se inicialmente considerar a região como um complexo mosaico de domínios gnáissicos-migmatíticos arqueano-paleoproterozóicos e faixas dobradas proterozóicas associados a granitóides e intensas deformações neoproterozóicas (Figura 3) (Brito Neves, 1975; Jardim de Sá, 1994).



Figura 3 - Mapa geológico da Província Borborema (modificado de Brito Neves et al., 2000).

\section{Aquisição de dados e metodologia}

Os dados foram registrados em sismômetros de período curto modelo S13J (vertical, NS e EW) e de estações broadband (banda larga) modelo KS2000M, com registrador SMART24® e por estações da Reftek pertencentes ao Pool de Equipamentos Geofísicos do
Brasil (PEGBr), sediado no Observatório Nacional e com financiamento da PETROBRAS. Cada estação da Reftek era composta por um sensor triaxial L4C3D (Sercel) e um registrador DAS 130 (Reftek).

As principais ferramentas metodológicas para a realização deste trabalho são o Seismic Analysis Code (SAC) para leitura e processamento dos registros digitais disponíveis no LabSis/UFRN (Laboratório Sismológico da UFRN) e o HYPO71 (Lee \& Lahr, 1975), para determinação dos parâmetros do modelo, o qual localiza o hipocentro com a minimização das diferenças entre os tempos de chegada observados e teóricos das ondas sísmicas. Com isso, utiliza-se um método iterativo de mínimos quadrados desenvolvido por Geiger (1910). Este método utiliza os tempos de chegada das ondas $\mathrm{P}$ e S de cada estação para determinar um hipocentro preliminar. Assim, ele faz aproximações sucessivas de modo a encontrar o hipocentro verdadeiro. Para utilização desta técnica faz-se necessário adotar um modelo de velocidades inicial. A maioria dos programas de determinação hipocentral utiliza o método Geiger.

\section{Seleção de sismos e escolha do epicentro}

Foram selecionados eventos que ocorreram no na Província Borborema entre 2001 a 2011 com magnitude acima de 3.0 e que tiveram epicentros bem determinados por redes locais de estações. A princípio foram escolhidos 12 eventos com incertezas horizontais de no máximo $5 \mathrm{~km}$ (Tabela 1). O evento com a localização mais bem determinada foi o de Tabuleiro Grande - RN em 2007 com erro horizontal de $2 \mathrm{~km}$.

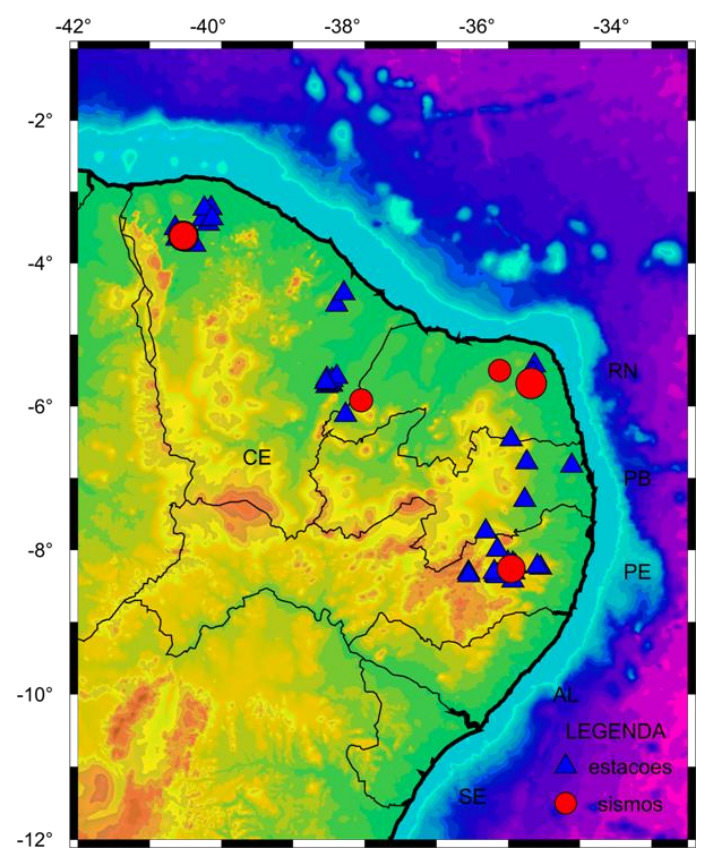

Figura 4 - Epicentros (círculos) e estações sismográficas (triângulos) utilizadas para a determinação do modelo de velocidades de onda $P$. 
Tabela 1 - Epicentros dos sismos regionais escolhidos para o modelo de velocidade de onda $P$.

\begin{tabular}{|c|c|c|c|l|c|c|c|c|c|c|}
\hline № & ANO & MÊS & DIA & \multicolumn{1}{|c|}{ LOCAL } & MAG & LAT & LONG & $\begin{array}{c}\text { Erro } \\
(\mathbf{k m})\end{array}$ & $\begin{array}{c}\text { PROF } \\
(\mathbf{k m})\end{array}$ & FONTE \\
\hline 1 & 2006 & Jul & 20 & São Caetano - PE & 3.3 & -8.23 & -36.15 & 5 & 6 & \\
\hline 2 & 2007 & Mar & 22 & Caruaru - PE & 3.9 & -8.26 & -35.96 & 5 & - \\
\hline 3 & 2007 & Set & 13 & Tabul. Grande - RN & 3.2 & -5.92 & -38.05 & 2 & 5 \\
\hline 4 & 2008 & Fev & 17 & Sobral - CE & 3.6 & -3.62 & -40.53 & 5 & - & \\
\hline 5 & 2008 & Fev & 29 & Sobral - CE & 3.5 & -3.62 & -40.53 & 5 & - & Boletim \\
\hline 6 & 2008 & Abr & 04 & Sobral - CE & 3.9 & -3.62 & -40.53 & 5 & - & Sísmico \\
\hline 7 & 2008 & Mai & 01 & Sobral - CE & 3.1 & -3.62 & -40.53 & 5 & - & Brasileiro - \\
\hline 8 & 2008 & Mai & 21 & Sobral - CE & 4.2 & -3.62 & -40.53 & 5 & - & Catálogo IAG \\
\hline 9 & 2008 & Mai & 21 & Sobral - CE & 3.9 & -3.62 & -40.53 & 5 & 5 \\
\hline 10 & 2010 & Jan & 09 & Taipu - RN & 3.5 & -5.68 & -35.68 & 5 & 10 \\
\hline 11 & 2010 & Jan & 11 & Taipu - RN & 4.3 & -5.68 & -35.68 & 5 & 10 & \\
\hline 12 & 2010 & Dez & 04 & Pedra Preta - RN & 3.1 & -5.50 & -36.12 & 3 & 5 & \\
\hline
\end{tabular}

Os eventos selecionados foram registrados nas redes: Milênio, ETINCT, Caruaru - PE, São Caetano - PE, Castanhão - CE, Santana do Acarau - CE, Taipu - RN, Sobral - CE e Pedra Preta - RN e a maior parte tem uma boa qualidade. A Figura 5 mostra o sismo de magnitude 4.3, em Taipu - RN, registrado na estação CSBF da rede de Castanhão.

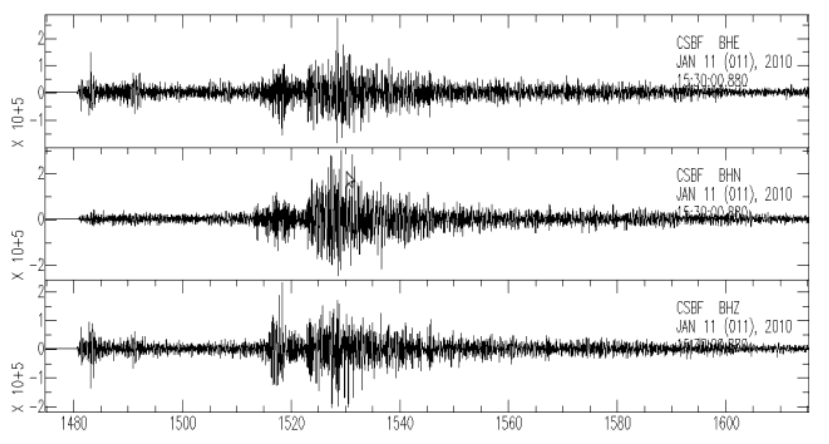

Figura 5 - Sismograma do evento em Taipu - RN, do dia 11/01/2010, registrado na estação $C S B F$ da rede Castanhão.

\section{Discussão e Conclusões}

Os sismos selecionados estão geograficamente concentrados, principalmente, no Rio Grande do Norte, Ceará e no agreste pernambucano. A seleção de sismos com magnitude maior que 3.0 permite que o evento seja, ainda, registrado em várias estações fazendo com que aumente a confiabilidade do modelo. Além disso, este estudo permitirá elaborar catálogos confiáveis de sismos para uso das redes sismográficas em funcionamento e outras que poderão ser instaladas na Província Borborema.

\section{Agradecimentos}

Nossos agradecimentos ao técnico Eduardo Menezes pelo empenho na manutenção e instalação das redes sismográficas. Ao Neymar P. da Costa por sua disponibilização e organização dos dados no LabSis/UFRN.

\section{Referências}

Ardito, J. C. - Determinação de Epicentros de Sismos Regionais. Trabalho de Graduação, IAG-USP. 2009

Brito Neves, B.B., 1975. Regionalização Geotectônica do Precambriano Nordestino. Tese de Doutorado, IAG/USP, São Paulo, $198 f$.

Geiger, L., 1910. Probability method for the determination of earthquake epicenters fron the arrival time only. Bull. St. Louis Univ. 8, 60-71.

Herrin, E., 1968. Seismological Tables for P phases. Bull. Seism. Soc. Am., 58: 1193-1241.

Jeffreys, H. \& Bullen, K. E., 1940. Seismological tables. British Association, Gray milne trust.

Kennett B.L.N., Engdahl E.R. \& Buland R. (1995) Constraints on seismic velocities in the earth from travel times Geophys. J. Int, 122, 108-124.

Kwitko, R., Assumpção, M. 1990. Modelo de velocidades para o manto superior no Brasil e determinação de epicentros regionais. Proceedings, 360 Congr. Bras. Geol., Natal, RN, 5, 2464-2469.

Lee, W. H. K., Lahr, J. C. 1975, HYPO71 (revised): A computer program for determined hypocenter, magnetude an first motion pattern of local earthquakes. U. S. Geol. Survey, open-file report, 75-311.

Neto, H. C. - Estudo da atividade sísmica em São Caetano - PE em 2007. Dissertação de Mestrado, UFRN. 2009

Novo Barbosa, M. F., Estimativas de Espessura Crustal na Província Borborema (NE/Brasil) através da Função do Receptor. 2008. Dissertação de Mestrado. Universidade Federal do Rio Grande do Norte

Jardim de Sá, E.F., 1994. A Faixa Seridó (Província Borborema, NE Brasil) e o seu significado geodinâmico na cadeia Brasiliana/Pan-Africana. Tese de Doutorado, UnB, Brasília, $803 f$. 